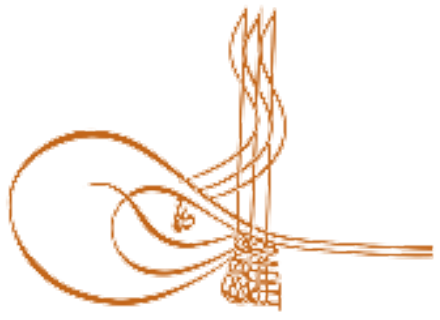

www.turkishstudies.net/education
Turkish Studies - Educational Sciences

eISSN: $2667-5609$

Research Article / Araştırma Makalesi

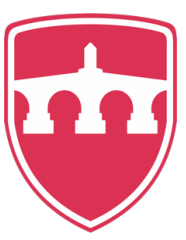

INTERNATIONAL BALKAN

UNIVERSITY Sponsored by IBU

\title{
Fen Bilgisi, Sınıf ve Okulöncesi Öğretmen Adaylarının Model ve Modelleme, Yaşam Becerileri ve Bilişötesi Farkındalıklarına Ait Görüşlerinin İncelenmesi*
}

\author{
Investigated of Elementary Science, Primary School and Pre-School Prospective Teachers' Views \\ on Model and Modeling, Life Skills and Metacognitive Awareness
}

\author{
Yaşar Gökçek $^{* *}$ - Yusuf Zorlu***
}

\begin{abstract}
In this study, the prospective teachers in the department of elementary science (EST), primary school (PST) and pre-school (PT) teacher should determine their views on model and modeling, life skills and metacognitive awareness and aimed to be investigated according to the department. The survey research method was used in this study. The sample of the study was found in the 3rd grade 148 (45 EST, 53 PST and 50 PT prospective teachers) and the 4th grade 268 (51 EST, 94 PST and 123 PT prospective teachers) of the faculty of education at a state university in the Western Anatolia region of Turkey in the 2018-2019 academic year. Research data were obtained using the Model and Modeling Scale, Life Skills Scale and Metacognitive Awareness Inventory. The data obtained from the scales were analyzed by multiple variances (MANOVA) and investigated according to the departments. When the findings of the study were investigated, the elementary science prospective teachers had better views on the model and modeling than the primary school and preschool prospective teachers. According to the findings from the Metacognitive Awareness Inventory, the knowledge and the elementary science and pre-school prospective teachers' metacognitive awareness was better than that of the primary school prospective teachers. According to the findings obtained from the Life Skills Scale, the prospective teachers' views were equal on the basis of the departments. In addition, the elementary science, primary school and pre-school prospective teachers' are not sufficiently adequate according to their views on model and modeling, life skills and metacognitive awareness. High-level thinking with more use of learning models, methods and techniques in which they can model in undergraduate education
\end{abstract}

\footnotetext{
* Bu çalışma Yusuf Zorlu'nun danışmanlığında Yaşar Gökçek tarafından yazılan "Öğretmen adaylarının model ve modelleme ile yaşam becerilerine ait görüşlerinin bilişötesi farkındalıklarıyla arasındaki ilişkilerin incelenmesi” başlıklı yüksek lisans tezinden türetilmiştir.

${ }^{*}$ Bu çalışmanın verileri 2018-2019 eğitim-öğretim yılında toplanmış ve dergiye 2019 yılında gönderilmiştir.

** Bilim Uzmanı, Dumlupınar Üniversitesi, Eğitim Bilimleri Enstitüsü, Fen Bilgisi Eğitimi Bölümü

Scientist, Dumlupinar University, Institute of Educational Sciences, Department of Science Education

ORCID 0000-0002-7684-6382

yzorlu2335@gmail.com

*** Dr. Öğr. Üyesi, Dumlupınar Üniversitesi, Eğitim Fakiltesi, Fen Bilgisi Eğitimi Bölümü

Asist. Prof., Dumlupinar University, Faculty of Education, Department of Science Education

ORCID 0000-0002-4203-0908

yusuf.zorlu@dpu.edu.tr

Cite as/ Atıf: Gökçek, Y. \& Zorlu, Y. (2020). Fen bilgisi, sınıf ve okulöncesi öğretmen adaylarının model ve modelleme, yaşam becerileri ve bilişötesi farkındalıklarına ait görüşlerinin incelenmesi, Turkish Studies - Education, 15(2), 817830. https://dx.doi.org/10.29228/TurkishStudies.40572

Received/Geliş: 15 January/Ocak 2020

Accepted/Kabul: 05 March/Mart 2020

Checked by plagiarism software

Copyright $($ INTAC LTD, Turkey 
and include life and scientific process skills while educating the elementary science, primary school and preschool prospective teachers can be provided.

Structured Abstract: In the literature, the subject of model and modeling is usually included in the views of teachers and students. The research has focused on the knowledge, skill levels, the impact of model and modeling on the nature of science, the benefits of model and modeling methods (Aslan and Yadigaroğlu, 2013; Aydın Güç, 2015; Batı, 2014; Krell and Krüger 2018; Korkmaz, 2010; Lee and Jones 2017; Özdemir, 2017; Zorlu and Sezek, 2019). In the relevant field of metacognitive awareness, the effects of student-centered approaches and programs on the development of metacognitive awareness of education supporters such as model and modeling, and negative situations such as anxiety are determined (Çiftçi, 2012; Deniz, 2017; Erenler, 2017; Hıdıroğlu, Bukova-Güzel, 2015; Kuvanç, 2014; Şahin, 2015). It was determined to determine the development of metacognitive awareness level according to class levels and to determine the effects of metacognitive strategies on the development of students' metacognitive awareness levels, academic achievements and self-awareness skills (Jaafar and Ayup, 2010; Weaver, 2012). In addition, the relationship between class levels and metacognitive awareness levels has been investigated in related literature (Tüysüz, Karakoyun ve Bilgin, 2008). When investigated in the literature on life skills, it was observed that research sample groups were usually composed of teachers and students. In the literature, teachers' thoughts about life skills were determined, and internal and external factors affecting the development of life skills of the students were investigated (Erduran-Avcı and Kamer, 2018; Özata-Yücel and Kanyılmaz, 2018; Özdemir, 2015; Zorlu, Zorlu and Dinç, 2019).

Model and modeling, metacognitive awareness and life skills are investigated according to many different variables in the literature and different results presented is observed. However, these studies are usually aimed at one or two subjects. At this point, it is observed that studies investigating model and modeling, metacognitive awareness and life skills subjects together and on the basis of undergraduate-level departments are not sufficient. In addition, model and modeling to acquire life skills (Bat1, 2014; Zorlu and Sezek, 2019), model and modeling and life skills are also effective in developing metacognitive awareness (Hidıroğlu and Bukova-Güzel, 2015; Özer-Keskin, 2010; Zorlu, Zorlu and Dinç, 2019). In this context, it can be considered that model and modeling, life skills and metacognitive awareness can be investigated together. In this study, which took into account these situations, the prospective teachers in the department of elementary science (EST), primary school (PST) and pre-school (PT) teacher should determine their views on model and modeling, life skills and metacognitive awareness and intended to be investigated according to the sections.

For this aim, "Is there a statistical difference among the elementary science, primary school and preschool prospective teachers' views on model and modeling, life skills and metacognitive awareness" research question response sought.

The survey research method was used in this study. The sample of the study was found in the 3rd grade 148 (45 EST, 53 PST and 50 PT prospective teachers) and the 4th grade 268 (51 EST, 94 PST and 123 PT prospective teachers) of the faculty of education at a state university in the Western Anatolia region of Turkey. Research data were obtained using the Model and Modeling Scale, Life Skills Scale and Metacognitive Awareness Inventory. The data obtained from the scales were analyzed by multiple variances (MANOVA) and investigated according to the departments.

When the findings of the study were investigated, the elementary science prospective teachers had better views on the model and modeling than the primary school and pre-school prospective teachers. When the literature is investigated, there are studies showing similar (Yetim, 2015) and difference (Ergin, Özcan ve Sar1, 2012) with the results obtained from this study. According to the findings from the Metacognitive Awareness Inventory, the knowledge and the elementary science and pre-school prospective teachers' metacognitive awareness was better than that of the primary school prospective teachers. When the literature is investigated, there are studies showing parallels (Tüysüz, Karakuyu and Bilgin, 2008) and difference (Sezgin-Memnun and Akkaya, 2012) with the results obtained from this research. According to the findings obtained from the Life Skills Scale, the prospective teachers' views were equal on the basis of the departments. In addition, the elementary science, primary school and pre-school prospective teachers' are not sufficiently adequate according to their views on model and modeling, life skills and metacognitive awareness. High-level thinking with more use of learning models, methods and techniques in which they can model in undergraduate

Turkish Studies - Education, 15(2) 
education and include life and scientific process skills while educating the elementary science, primary school and pre-school prospective teachers can be provided.

Keywords: Science Education, Metacognitive Awareness, Model and Modeling, Life Skills, Prospective Teachers

Öz: Bu çalışmada fen bilgisi, okul öncesi ve sınıf öğretmenliği bölümündeki öğretmen adaylarının model ve modelleme, yaşam becerileri ve bilişötesi farkındalık konularındaki görüşlerinin belirlenmesi ve bölümlere göre incelenmesi amaçlanmıştır. Araştırmada tarama araştırma yöntemi kullanılııştır. Araştırmanın örneklemi 2018-2019 eğitim-öğretim y1lında Türkiye'de Batı Anadolu Bölgesinde bulunan bir devlet üniversitesinin eğitim fakültesinin 3. sınıfında öğrenim gören 148 (45 FBÖ, 53 SÖ ve 50 OÖÖ adayı) ve 4. sınıfında öğrenim gören 268 (51 FBÖ, 94 SÖ ve 123 OÖÖ adayı) öğretmen adayından oluşmaktadır. Araştırma verileri "Model ve Modelleme Ölçeği", "Yaşam Becerileri Ölçeği" ve "Biliş̧ötesi Farkındalık Envanteri" kullanılarak elde edilmiştir. Ölçeklerden elde edilen veriler çoklu varyans analizi (MANOVA) yapılarak bölümlere göre bakılmıştır. Araştırmadan elde edilen bulgular incelendiğinde fen bilgisi öğretmen adaylarının model ve modelleme konusunda sınıf ve okul öncesi öğretmen adaylarına göre görüşlerinin daha iyi olduğu tespit edilmiş̧ir. Bilişötesi Farkındalık Envanterinden elde edilen bulgulara göre fen bilgisi ve okul öncesi öğretmen adaylarının biliş̧̈tesi farkındalıklarının sınıf öğretmen adaylarına göre daha iyi seviyede olduğu belirlenmiştir. Yaşam Becerileri Ölçeğinden elde edilen bulgulara göre bölümler bazında öğretmen adaylarının görüşlerinin denk olduğu sonucuna ulaşılmıştır. Ayrıca, fen bilgisi, sınıf ve okul öncesi öğretmen adaylarının model ve modelleme, yaşam becerileri ve bilişötesi farkındalık konularındaki görüşlerine göre yeterli düzeyde olmadıkları görülmektedir. Fen bilgisi, sınıf ve okul öncesi öğretmenleri yetiştirirken lisans eğitiminde modelleme yapabilecekleri, yaşam ve bilimsel süreç becerilerini dahil edebilecekleri öğrenme model, yöntem ve tekniklerin daha fazla kullanılması ile üst düzey düşünmeleri sağlanabilir.

Anahtar Kelimeler: Fen Eğitimi, Bilişötesi Farkındalık, Model ve Modelleme, Öğretmen Adayı, Yaşam Becerileri

\section{Giriş}

Günümüzde ilerlemenin temelini oluşturan fen bilimlerine büyük önem verilmektedir (Ayas, 1995; Ünal, Çoştu ve Karataş, 2004). Bu doğrultuda fen eğitimi okul öncesi eğitim seviyesinden itibaren öğrencilere verilmeye başlanmalıdır. Çünkü çocuklarda bu dönemde bilişsel, duyusal ve zihinsel gelişim çok hızlıdırve temel fen kavramları oluşmaktadır (Karamustafaoğlu ve Kandaz, 2006; Kalley ve Psillos, 2001). Bu dönemde çocuklara gözlem yapma, soru sorma, araştırma yapma ve keşfetme gibi etkinliklerle bilimsel süreç becerilerinin gelişimi sağlanmalı, üst seviye eğitim kurumlarında okutulacak fen bilgisi derslerine temel oluşturulmalıdır (Milli Eğitim Bakanlığı [MEB], 2016).

Öğrenciler öğrenme ortamında bilimsel süreç becerilerini kullanarak model ve modelleme teknikleriyle kendi öğrenmelerini kendileri yapılandırırlar. Fakat model ve modelleme tekniklerinin kullanılması ve yorumlanması aşamasında sadece bilimsel süreç becerileriyle bu süreçleri açıklamak yetersizdir. Çünkü nerede hangi stratejinin kullanacağını öğrencilerin bilişötesi becerileri belirler (Altunsoy, 2012). Bu beceriler, kaliteli öğrenmelerin gerçekleştirilebilmesi için tüm öğrenme süreçlerini düzenler (Ülger, 2004). Bilişötesi beceriler tüm insanlarda var olan becerilerdir. Önemli olan bu becerilerle ilgili farkındalık oluşturabilmek ve becerileri ortaya çıkarabilmektir (Adak, 2016; Kuvanç, 2014; Şahin 2015). Fen derslerinde öğrencileri çağın gereklerine uygun araştıran, sorgulayan, bilim adamının kullandığı problem çözme becerilerini kullanabilen bireyler olarak yetiştirebilmek için fen öğretim programlarında son yıllarda gelişmiş ülkelerde olduğu gibi ülkemizde de düzenlemelere gidilmiştir. Bu amaçla ülkemizde fen derslerinde öğrencilerin bireysel farklılıkları dikkate alınarak beceri, değer ve tutum kazandırılması, üst bilişsel becerilerini kullanarak anlamlı ve kalıcı öğrenmenin sağlaması önceki öğrenmelerle yeni öğrenmelerini ilişkilendirip, öğrendiklerinin günlük hayata uygulayabilecekleri etkinlikler şeklinde öğretim programları tekrar 
düzenlenmiştir (MEB, 2005, 2018). Yirmi birinci yüzyılda geleceğin teminatı gençleri sadece akademik alanda yetiştirmek yeterli olmayacaktır. Akademik alandaki başarı sosyal alandaki faaliyetlerdeki başarılarla pekiştirilmelidir (Murat, 2018). Sosyal alanda başarılı olabilmek ise hiç şüphesiz yaşamın iyi planlanması ile mümkün olacaktır (Çolak, 2018). Yaşam planlamasının sağliklı yapılabilmesi için öğrencilere analitik düşünme, karar verme, yaratıcılık, girişimcilik, iletişim ve takım çalışması gibi yaşam becerilerini içeren iyi bir eğitim verilmesi gerekmektedir (Ümmet ve Demirci, 2017). Yaşam ve kariyer becerileri, toplumların sosyal hayatta birlikte yaşamasını sağlayan, farklı yönlerin avantaja dönüştürülmesini öngören, günümüz dünyasında var olmayı sağlayan, değişen hayat şartlarına uyum sağlamayı zorunlu kılan becerilerdir. Görev ve aidiyet duygusu üst düzeyde olan kişilerden oluşan toplulukların temelini oluşturur. Küreselleşmeye karşı ulusal toplumların en büyük silahıdır (P21, 2015). Curtiss ve Warren (1974), yaşam becerileri ile ilgili yapmış oldukları araştırmalarında yaşam becerilerini kısaca, kişinin hayatta idare etmekle yükümlü olduğu alanlar şeklinde ifade etmişlerdir (Akt: Özdemir, 2015). Yaşam ve kariyer becerilerine sahip olan bireylerin özgüveni yüksek, girişken, sorumluluk sahibi bireyler olarak yetişmesi beklenmekte ve böylece mesleki hayata hazır olma ve kariyer planlamayı iş hayatının bir bölümü olarak alıp kişisel gelişime önem verme söz konusu olabilmektedir (Trilling ve Fadel, 2009'den Akt: Göksun-Orhan ve Kurt-Aşkım, 2017).

İlgili alanyazında model ve modelleme konusu ile genellikle öğretmen ve öğrenci görüşlerine yer verilmiştir. Öğrenci görüşlerinin incelendiği araştırmaların çoğunluğunda örneklem gurubu olarak öğretmen adayları kullanılmıştır. Araştırmalarda örneklem grupları üzerinde model ve modelleme konusundaki bilgi, beceri düzeyleri, model ve modellemenin bilimin doğasına etkisi, model ve modelleme yöntemlerinin yararları konuları ele alınmıştır (Aslan ve Yadigaroğlu, 2013; Aydın Güç, 2015; Bat1, 2014; Krell ve Krüger 2018; Korkmaz, 2010; Lee ve Jones 2017; Özdemir, 2017; Zorlu ve Sezek, 2019). Bilişötesi farkındalık konusu ilgili alanyazında, öğrenci merkezli yaklaşım ve programların, model ve modelleme gibi eğitimi destekleyicilerin, kaygı gibi olumsuz durumların bilişötesi farkındalık gelişimine etkisi belirlenmeye çalışılmıştır (Çiftçi, 2012; Deniz, 2017; Erenler, 2017; Hıdıroğlu, Bukova-Güzel, 2015; Kuvanç, 2014; Şahin, 2015). Sinıf düzeylerine göre bilişötesi farkındalık düzeyi gelişimlerini belirlemek ve bilişötesi stratejilerin öğrencilerin bilişötesi farkındalık düzeylerinin gelişimine, akademik başarılarına, öz farkındalık becerilerine etkisi tespit edilmeye çalışılmıştır (Jaafar ve Ayup, 2010; Weaver, 2012). Ayrıca sınıf seviyeleri ile bilişötesi farkındalık düzeyleri arasındaki ilişki de ilgili alan yazılarında araştırılmıştır (Tüysüz, Karakoyun ve Bilgin, 2008). Yaşam becerileri konusu ile ilgili alanyazın incelendiğinde, araştırma örneklem guruplarının genellikle öğretmen ve öğrencilerden oluşturulduğu gözlenmiştir. İlgili alan yazılarında öğretmenlerin yaşam becerileri ile ilgili düşünceleri belirlenmeye çalışılmış, öğrencilerin ise yaşam becerileri gelişimine etki eden iç ve dış faktörler araştırılmıştır (Erduran-Avcı ve Kamer, 2018; Özata-Yücel ve Kanyılmaz, 2018; Özdemir, 2015; Zorlu, Zorlu ve Dinç, 2019).

Model ve modelleme, bilişötesi farkındalık ve yaşam becerileri konularının ilgili alanyazında birçok farklı değişkene göre incelendiği ve farklı sonuçların ortaya konduğu görülmektedir. Ancak bu araştırmalar genelde tek veya iki konuya yönelik olarak yapılmıştır. Bu noktada model ve modelleme, bilişötesi farkındalık ve yaşam becerileri konularını birlikte ve lisans düzeyinde bölümler bazında inceleyen çalışmaların yeterli düzeyde olmadığı görülmektedir. Ayrıca model ve modelleme yaşam becerileri kazandırmada (Bat1, 2014; Zorlu ve Sezek, 2019), model ve modelleme ile yaşam becerileri de bilişötesi farkındalıkları geliştirmede etkilidir (Hıdıroğlu ve Bukova-Güzel, 2015; Özer-Keskin, 2010; Zorlu, Zorlu ve Dinç, 2019). Bu bağlamda model ve modelleme, yaşam becerileri ve bilişötesi farkındalık konularının birlikte incelenebileceği düşünülebilir. Bu durumlar göz önüne alınarak gerçekleştirilen bu çalışmada fen bilgisi, okul öncesi ve sınıf öğretmenliği bölümündeki öğretmen adaylarının model ve modelleme, yaşam becerileri ve bilişötesi farkındalık konularındaki görüşlerinin belirlenmesi ve bölümlere göre incelenmesi amaçlanmıştır. 
$\mathrm{Bu}$ amaç doğrultusunda "Fen bilgisi, okul öncesi ve sınıf öğretmenliği bölümündeki öğretmen adaylarının model ve modelleme, yaşam becerileri ve bilişötesi farkındalık konularındaki görüşleri arasında istatistiksel olarak fark var mıdır?" araştırma sorusuna yanıt aranmaya çalışılmıştır.

\section{Yöntem}

$\mathrm{Bu}$ bölümde araştırmanı modeli, evren ve örneklem, veri toplama araçları, verilerin toplanması ve verilerin analizine yer verilmiştir.

\section{Araştırmanın Yöntemi}

Çalışmada tarama araştırma yöntemi kullanılmıştır. Tarama araştırma yönteminde geçmişte ya da halen var olan bir durumu olduğu şekliyle tespit etmek amaçlanmaktadır (Karasar, 2011). Bu araştırmada okul öncesi (OÖÖ), sınıf (SÖ) ve fen bilgisi öğretmen (FBÖ) adaylarının model ve modelleme, yaşam becerileri ve bilişötesi farkındalık konularındaki görüşlerinin bölümlere göre incelenmesi amacıyla tarama araştırma yöntemi kullanılmıştır.

\section{Evren ve Örneklem}

$\mathrm{Bu}$ araştırmada örneklem, amaçlı örnekleme yöntemiyle belirlenmiştir. Örneklemede amaç, lisans eğitiminde fen bilgisi ile ilgili dersleri almakta olan ve meslek hayatında fen bilgisi ile ilişkili dersleri veya konuları verecek olan öğretmen adaylarının belirlenmesidir. Bu amaç doğrultusunda fen bilgisi, sınıf ve okul öncesi öğretmen adayları araştırmaya dâhil edilmiştir. Araştırmanın örneklemi Türkiye'de Batı Anadolu Bölgesinde bulunan bir devlet üniversitesinin eğitim fakültesinin 3. sınıfında öğrenim gören 148 ( 45 FBÖ, 53 SÖ ve 50 OÖÖ) ve 4. sınıfında öğrenim gören 268 (51 FBÖ, 94 SÖ ve 123 OÖÖ) öğretmen adayından oluşmaktadır.

\section{Veri Toplama Araçları}

Araştırma verileri "Model ve Modelleme Ölçeği", "Yaşam Becerileri Ölçeği" ve "Bilişötesi Farkındalık Envanteri" kullanılarak elde edilmiştir. Söz konusu veri toplama araçlarından Model ve Modelleme Ölçeği, Yaşam Becerileri Ölçeği ve Bilişötesi Farkındalık Envanteri aşağıda ifade edilmiştir.

\section{Model ve Modelleme Ölçeği}

Güneş, Gülçiçek ve Bağcı (2004) tarafından model ve modelleme hakkındaki düşünceleri belirlemek amacıyla geliştirilmiş, 30 madde ve 6 alt gruptan oluşturulmuştur. Ölçeğin alt grupları ise, Çoklu Temsiller Olarak Modeller, Tam bir Kopya Olarak Modeller, Açıklayıcı Araçlar Olarak Modeller, Bilimsel Modellerin Kullanımı, Modellerin Yapısının Değişimi ve Model Örnekleri şeklinde ifade edilmiştir (Güneş, Gülçiçek ve Bağc1, 2004). Model ve Modelleme Ölçeği güvenirlik çalışması Aslan ve Yadiğaroğlu (2013) tarafından yapılmış, güvenirlik katsayısı .76 olarak hesaplanmıştır. Bu çalışmada ise güvenirlik katsayısı .87 olarak hesaplanmıştır.

\section{Bilişötesi Farkındalık Envanteri}

Schraw ve Dennison (1994) tarafından bireylerin bilişötesi farkındalık düzeylerini belirlemek amacıyla geliştirilmiş, beşli likert tipte 52 madde, iki boyut ve sekiz alt faktörden oluşturulmuştur. Akın, Abacı ve Çetin (2007) tarafından 52 madde sekiz alt boyuttan oluşturularak Türkçe'ye uyarlanmıştır. Envanterin "Bilişin Bilgisi" alt boyutları; Açıklayıcı (Bildirimsel) Bilgi, Prosedürel (İşlemsel) Bilgi, Durumsal Bilgi, "Bilişin Düzenlenmesi" alt boyutları; Planlama, İzleme, Değerlendirme, Hata Ayıklama ve Bilgi Yönetme şeklinde ifade edilmiştir. Ölçeğin Cronbach's Alpha içtutarlılık katsayısı Türkçe formunda tüm ölçek için .94 olarak bulunmuştur. Bu çalışmada ise güvenirlik katsayısı .95 olarak hesaplanmıştır.

\section{Yaşam Becerileri Ölçeği}


Bolat ve Balaman (2017) tarafindan, öğretmen adaylarının yaşam becerileri konusunda düşüncelerini belirlemek amaciyla geliştirilmiştir. Ölçek, beşli likert tipte 30 madde, beş alt boyuttan oluşturulmuştur. Ölçeğin alt boyutları ise Stresle ve Duygularla Baş Etme, Empati ve Özfarkındalık, Karar Verme ve Problem Çözme, Yaratıcı ve Eleştirel Düşünme ve İletişim ve Kişilerarası İlişki şeklinde ifade edilmiştir. Bolat ve Balaman (2017) araştırmasında YBÖ'nin Cronbach's Alpha içtutarlılık katsayısını .90 olarak hesaplamıştır. Bu araştırmada güvenirlik katsayısı değeri .89 olarak hesaplanmıştır.

\section{Verilerin Analizi} bakılmıştır.

Ölçeklerden elde edilen veriler çoklu varyans analizi (MANOVA) yapılarak bölümlere göre

\section{Bulgular}

Okul öncesi öğretmenliği (OÖÖ), sınıf öğretmenliği (SÖ) ve fen bilgisi öğretmenliği (FBÖ) bölümlerinde öğrenim gören öğretmen adaylarına Model ve Modelleme Ölçeği, Yaşam Becerileri Ölçeği ve Biliş̧ötesi Farkındalık Envanteri uygulanmıştır. Ölçeklerden elde edilen verilerin betimsel istatistiksel değerleri Tablo 1'de verilmiştir.

Tablo 1: Ölçeklerden Elde Edilen Verilerin Betimsel İstatistik Sonuçları

\begin{tabular}{lllll}
\hline Ölçekler & Bölümler & $\mathrm{N}$ & $\overline{\mathrm{X}}$ & $\mathrm{SS}$ \\
\hline Model ve Modelleme & OÖÖ & 173 & 112.00 & 12.84 \\
& SÖ & 147 & 112.06 & 12.32 \\
& FBÖ & 96 & 117.35 & 13.22 \\
\hline Yaşam Becerileri & OÖÖ & 173 & 111.30 & 15.82 \\
& SÖ & 147 & 108.77 & 12.05 \\
& FBÖ & 96 & 112.31 & 13.18 \\
\hline Bilişötesi Farkındalık & OÖÖ & 173 & 194.52 & 28.37 \\
& SÖ & 147 & 185.54 & 23.08 \\
& FBÖ & 96 & 196.94 & 27.08 \\
\hline
\end{tabular}

Tablo 1'e göre, Model ve Modelleme Ölçeğinden elde edilen verilerde fen bilgisi öğretmen adaylarının aldıkları puanların diğer bölümlerdeki öğretmen adaylarına göre daha yüksek olduğu görülmektedir. Yaşam Becerileri ve Bilişötesi Farkındalık Ölçeklerinden elde edilen verilerde sınıf öğretmen adaylarının aldıkları puanların diğer bölümlerdeki öğretmen adaylarına göre daha düşük olduğu görülmektedir. Öğretmen adaylarının yaşam becerilerine yönelik düşüncelerinin 5 üzerinden 3.63-3.74 arasında ve orta seviyede olduğu görülmektedir. Elde edilen farkın bölümler bazında anlamlı olup olmadığına bakmak için MANOVA analizi yapılmış ve sonuçlar Tablo 2'de verilmiştir.

Tablo 2: Ölçeklerden Elde Edilen Verilerin Bölümlere Göre MANOVA Sonuçları

\begin{tabular}{llllll}
\hline Varyans kaynağ1 & Wilks' Lamda & Hipotez df & Hata df & F & P \\
\hline Bölümler & .894 & 4.000 & 204.000 & 2.941 & .022 \\
\hline
\end{tabular}

Tablo 2'deki analiz sonuçları incelendiğinde; okul öncesi öğretmenliği (OÖÖ), sınıf öğretmenliği (SÖ) ve fen bilgisi öğretmenliği (FBÖ) bölümlerinde öğrenim gören öğretmen adaylarının ölçeklerden aldıkları puanlar arasında anlamlı farklılıklar olduğu tespit edilmiştir; $\mathrm{F}=2.941, \mathrm{p}<.05$. Ölçeklerden elde edilen verilerdeki grupların varyanslarının homojen olup olmadığına bakmak için homojenlik testi yapılmıştır; Model ve Modelleme Ölçeği: $p=.930$, Yaşam Becerileri Ölçeği: $p=.01$, Bilişötesi Farkındalık Envanteri: $p=.026$. Ortaya çıkan bu farkın hangi gruplar arasında olduğunu tespit etmek için çoklu karşıllaştırma testlerinden Model ve Modelleme Ölçeğinden elde edilen veriler için LSD, Yaşam Becerileri Ölçeği ve Bilişötesi Farkındalık Envanterinden elde edilen veriler için Dunnett $\mathrm{C}$ testine başvurulmuş ve sonuçlar Tablo 3 'te verilmiştir. 
Tablo 3: Ölçeklerden Elde Edilen Verilerin Öğretmen Adaylarının Bölümlerine Göre Çoklu Karşılaştırma Sonuçları

\begin{tabular}{|c|c|c|c|c|c|}
\hline Ölçek & (I)gruplar & (J)gruplar & Ortalama fark (I-J) & Standart hata & $\mathrm{p}$ \\
\hline \multirow{6}{*}{$\begin{array}{l}\text { Model ve } \\
\text { Modelleme }\end{array}$} & OÖÖ & SÖ.. & -.06 & 1.43 & .966 \\
\hline & & FBÖ & $-5.35^{*}$ & 1.62 & .001 \\
\hline & SÖ & OÖÖ & .06 & 1.43 & .966 \\
\hline & & FBÖ & $-5.29^{*}$ & 1.67 & .002 \\
\hline & FBÖ & OÖ & $5.35^{*}$ & 1.62 & .001 \\
\hline & & sö & $5.29^{*}$ & 1.67 & .002 \\
\hline Ölçek & (I)gruplar & (J)gruplar & Ortalama fark (I-J) & Standart hata & \\
\hline \multirow{6}{*}{$\begin{array}{l}\text { Yaşam } \\
\text { Becerileri }\end{array}$} & OÖÖ & SÖ & 2.5319 & 1.56065 & \\
\hline & & FBÖ & -1.0119 & 1.80470 & \\
\hline & SÖ & OÖÖ & -2.5319 & 1.56065 & \\
\hline & & FBÖ & -3.5438 & 1.67262 & \\
\hline & FBÖ & OÖÖ & 1.0119 & 1.80470 & \\
\hline & & SÖ & 3.5438 & 1.67262 & \\
\hline \multirow{6}{*}{$\begin{array}{l}\text { Bilişötesi } \\
\text { Farkındalık }\end{array}$} & OÖÖ & SÖ & $8.99^{*}$ & 2.88 & \\
\hline & & FBÖ & -2.41 & 3.51 & \\
\hline & SÖ & OÖÖ & $-8.99 *$ & 2.88 & \\
\hline & & FBÖ & $-11.40^{*}$ & 3.36 & \\
\hline & FBÖ & OÖÖ & 2.41 & 3.51 & \\
\hline & & SÖ & $11.40^{*}$ & 3.36 & \\
\hline
\end{tabular}

Tablo 3'teki veriler incelendiğinde, Model ve Modelleme Ölçeğinden elde edilen verilere göre fen bilgisi öğretmen adayları ile sınıf öğretmenliği ve okul öncesi öğretmen adayları arasında istatistiksel açıdan anlamlı farklılıklar olduğu görülmektedir $(\mathrm{p}<.05)$. Bilişötesi Farkındalık Envanterinden elde edilen verilere göre, sınıf öğretmen adayları ile fen bilgisi ve okul öncesi öğretmen adayları arasında istatistiksel olarak anlamlı farklıllklar olduğu tespit edilmiştir. Sınıf öğretmen adaylarının Bilişötesi Farkındalık Envanterinden diğer bölümlere göre daha düşük puan aldıkları görülmektedir $(\mathrm{p}<.05)$. Yaşam Becerileri Ölçeğinden elde edilen verilere göre öğretmen adaylarının bölümlere göre aralarında istatistiksel olarak anlamlı farklılıkların olmadığı görülmektedir ( $>$ >.05).

Öğretmen adaylarına uygulanan Model ve Modelleme Ölçeğinin faktörlerinden elde edilen verilere ANOVA analizi yapılmış ve sonuçlar Tablo 4'te verilmiştir. 
Tablo 4: Model ve Modelleme Ölçeğinin Faktörlerinden Elde Edilen Verilerin Öğretmen Adaylarının Bölümlerine Göre ANOVA Analizi Sonuçları

\begin{tabular}{|c|c|c|c|c|c|c|}
\hline Faktörler & Gruplar & $\begin{array}{r}\text { Karelerin } \\
\text { Toplamı } \\
\end{array}$ & SD & $\begin{array}{r}\text { Karelerin } \\
\text { Ortalamas1 } \\
\end{array}$ & $\mathrm{F}$ & $\mathrm{p}$ \\
\hline Çoklu Temsiller Olarak & Gruplar arası & 73.780 & 2 & 36.89 & 1.926 & .147 \\
\hline Modeller & $\begin{array}{l}\text { Grup içi } \\
\text { Toplam }\end{array}$ & $\begin{array}{l}7911.102 \\
7984.882\end{array}$ & $\begin{array}{l}413 \\
415\end{array}$ & 19.16 & & \\
\hline Tam bir Kopya Olarak & Gruplar arası & 193.886 & 2 & 96.94 & 4.229 & .015 \\
\hline Modeller & $\begin{array}{l}\text { Grup içi } \\
\text { Toplam }\end{array}$ & $\begin{array}{l}9466.335 \\
9660.221\end{array}$ & $\begin{array}{l}413 \\
415\end{array}$ & 22.92 & & \\
\hline Açıklayıcı Araçlar Olarak Modeller & $\begin{array}{l}\text { Gruplar arası } \\
\text { Grup içi } \\
\text { Toplam }\end{array}$ & $\begin{array}{r}94.812 \\
4089.410 \\
4184.221 \\
\end{array}$ & $\begin{array}{r}2 \\
413 \\
415 \\
\end{array}$ & $\begin{array}{r}47.41 \\
9.90\end{array}$ & 4.788 & .009 \\
\hline $\begin{array}{l}\text { Bilimsel Modellerin } \\
\text { Kullanımı }\end{array}$ & $\begin{array}{l}\text { Gruplar arası } \\
\text { Grup içi } \\
\text { Toplam }\end{array}$ & $\begin{array}{r}14.379 \\
1522.150 \\
1536.529 \\
\end{array}$ & $\begin{array}{r}2 \\
413 \\
415 \\
\end{array}$ & $\begin{array}{l}7.19 \\
3.69\end{array}$ & 1.951 & .143 \\
\hline $\begin{array}{l}\text { Modellerin Yapısının } \\
\text { Değişimi }\end{array}$ & $\begin{array}{l}\text { Gruplar arası } \\
\text { Grup içi } \\
\text { Toplam } \\
\end{array}$ & $\begin{array}{r}23.859 \\
1953.446 \\
1977.305 \\
\end{array}$ & $\begin{array}{r}2 \\
413 \\
415 \\
\end{array}$ & $\begin{array}{r}11.93 \\
4.73\end{array}$ & 2.522 & .082 \\
\hline Model Örnekleri & $\begin{array}{l}\text { Gruplar arası } \\
\text { Grup içi } \\
\text { Toplam }\end{array}$ & $\begin{array}{r}28.951 \\
2730.854 \\
2759.805 \\
\end{array}$ & $\begin{array}{r}2 \\
413 \\
415 \\
\end{array}$ & $\begin{array}{r}14.48 \\
6.61\end{array}$ & 2.189 & .113 \\
\hline
\end{tabular}

Tablo 4'teki ANOVA analizi sonuçları incelendiğinde, öğretmen adaylarının bölümleri arasında Tam bir Kopya Olarak Modeller ve Açıklayıcı Araçlar Olarak Modeller faktörlerinde istatistiksel açıdan anlamlı bir fark olduğu belirlenmiştir; TKM: $F_{(2,415)}=4.229 ; p=.015$. AAM: $\mathrm{F}_{(2,415)}=4.788 ; \mathrm{p}=.009$. Ortaya çıkan bu farkın hangi gruplar arasında olduğunu tespit etmek için çoklu karşılaştırma testlerinden LSD (gruplar arası varyansların homojenlik analizi sonucu: $p>.05$ ) testine başvurulmuş ve sonuçlar Tablo 5'te verilmiştir.

Tablo 5: Model ve Modelleme Ölçeğinin Faktörlerinden Elde Edilen Verilerinin Öğretmen Adaylarının Bölümlerine Göre Çoklu Karşılaştırma Sonuçları

\begin{tabular}{lllrrr}
\hline Faktörler & (I)gruplar & (J)gruplar & Ortalama fark (I-J) & Standart hata & $p$ \\
\hline Tam bir Kopya Olarak Modeller & OÖÖ & SÖ & .25 & .54 & .646 \\
& & FBÖ & $-1.49^{*}$ & .61 & .015 \\
& SÖ & Ö̈Ö & -.25 & .54 & .646 \\
& & FBÖ & $-1.73^{*}$ & .63 & .006 \\
& \multirow{2}{*}{ FBÖ } & OÖÖ & $1.49^{*}$ & .61 & .015 \\
& & SÖ & $1.73^{*}$ & .63 & .006 \\
\hline Açklayıc1 Araçlar Olarak Modeller & OÖÖ & SÖ & -.21 & .35 & .557 \\
& & FBÖ & $-1.21^{*}$ & .40 & .003 \\
& SÖ & Ö̈Ö & .21 & .35 & .557 \\
& & FBÖ & $-1.00^{*}$ & .41 & .016 \\
& \multirow{2}{*}{ FBÖ } & Ö̈Ö & $1.21^{*}$ & .40 & .003 \\
& & SÖ & $1.00^{*}$ & .41 & .016 \\
\hline
\end{tabular}

Tablo 5'teki veriler incelendiğinde, Tam bir Kopya Olarak Modeller ve Açılayıcı Araçlar Olarak Modeller faktörlerinde fen bilgisi öğretmen adayları ile sınıf ve okul öncesi öğretmen adayları arasında istatistiksel açıdan anlamlı farklılıklar olduğu tespit edilmiştir $(\mathrm{p}<.05)$. "Tam bir Kopya Olarak Modeller ve Açıklayıcı Araçlar Olarak Modeller" faktörlerinde fen bilgisi öğretmen adaylarının okul öncesi ve sınıf öğretmen adaylarına göre daha iyi oldukları söylenebilir.

Bilişötesi Farkındalık Envanterinin faktörlerinden elde edilen verilere ANOVA analizi yapılmış ve sonuçlar Tablo 6'da verilmiştir. 
Tablo 6: Bilişötesi Farkındalık Envanterinin Faktörlerinden Elde Edilen Verilerin Öğretmen Adaylarının Bölümlerine Göre ANOVA Analizi Sonuçları

\begin{tabular}{lllrrrr}
\hline Faktörler & Gruplar & $\begin{array}{l}\text { Karelerin } \\
\text { Toplamı }\end{array}$ & SD & $\begin{array}{r}\text { Karelerin } \\
\text { Ortalamas1 }\end{array}$ & F & p \\
\hline Biliş Bilgisi & Gruplar aras1 & 967.54 & 2 & 483.77 & 5.975 & .003 \\
& Grup içi & 33438.27 & 413 & 80.96 & & \\
& Toplam & 34405.80 & 415 & & & \\
\hline Bilişin Düzenlemesi & Gruplar aras1 & 4455.02 & 2 & 2227.51 & 6.644 & .001 \\
& Grup içi & 138465.21 & 413 & 335.27 & & \\
& Toplam & 142920.23 & 415 & & & \\
\hline
\end{tabular}

Tablo 6'daki ANOVA analizi sonuçları incelendiğinde, Bilişötesi Farkındalık Envanterinin faktörlerinden elde edilen verilerin öğretmen adaylarının bölümlerine göre istatistiksel olarak farkl11ıklar olduğu belirlenmiştir; Biliş Bilgisi: $\mathrm{F}_{(2,415)}=5.975 ; \mathrm{p}=.003$, Bilişin Düzenlenmesi: $\mathrm{F}_{(2,415)}=$ 6.644; $p=.001$. Ortaya çıkan bu farkın hangi gruplar arasında olduğunu tespit etmek için çoklu karşılaştırma testlerinden Dunnett C (Bilişin düzenlenmesine ait gruplar arası varyansların homojenlik analizi sonucu: $\mathrm{p}<.05$ ) ve LSD (bilişin bilgisine ait gruplar arası varyansların homojenlik analizi sonucu: $\mathrm{p}>.05$ ) testine başvurulmuş ve sonuçlar Tablo 7'de verilmiştir.

Tablo 7: Bilişötesi Farkındalık Envanterinin Faktörlerinden Elde Edilen Verilerin Öğretmen Adaylarının Bölümlerine Göre Çoklu Karşılaştırma Sonuçları (LSD)

\begin{tabular}{|c|c|c|c|c|c|}
\hline Faktörler & (I)gruplar & (J)gruplar & Ortalama fark (I-J) & Standart hata & $\mathrm{p}$ \\
\hline \multirow{6}{*}{ Bilişin Bilgisi } & \multirow{2}{*}{ ОÖÖ } & SÖ & $2.86^{*}$ & 1.01 & .005 \\
\hline & & FBÖ & -.76 & 1.16 & .509 \\
\hline & \multirow{2}{*}{ SÖ } & OÖÖ & $-2.86^{*}$ & 1.01 & .005 \\
\hline & & FBÖ & $-3.62^{*}$ & 1.18 & .002 \\
\hline & \multirow{2}{*}{ FBÖ } & OÖÖ & .76 & 1.16 & .509 \\
\hline & & SÖ & $3.62^{*}$ & 1.18 & .002 \\
\hline Faktör & (I)gruplar & (J)gruplar & Ortalama fark (I-J) & \multicolumn{2}{|c|}{ Standart hata } \\
\hline \multirow{6}{*}{$\begin{array}{l}\text { Bilişin } \\
\text { Düzenlenmesi }\end{array}$} & \multirow[t]{2}{*}{ OÖÖ } & SÖ & \multicolumn{2}{|l|}{$6.12^{*}$} & 1.99 \\
\hline & & FBÖ & \multicolumn{2}{|l|}{-1.66} & 2.46 \\
\hline & \multirow[t]{2}{*}{ SÖ } & OÖÖ & \multirow{2}{*}{\multicolumn{2}{|c|}{$\begin{array}{l}-6.12^{*} \\
-7.78^{*}\end{array}$}} & 1.99 \\
\hline & & FBÖ & & & 2.35 \\
\hline & \multirow[t]{2}{*}{ FBÖ } & OÖÖ & \multirow{2}{*}{\multicolumn{2}{|c|}{$\begin{array}{r}1.67 \\
7.78^{*}\end{array}$}} & 2.46 \\
\hline & & SÖ & & & 2.35 \\
\hline
\end{tabular}

Tablo 7'deki Bilişötesi Farkındalık Envanterinin Faktörlerinden elde edilen verilere ait çoklu karşılaştırma analizi sonuçları incelendiğinde, "Bilişin Bilgisi" ve "Bilişin Düzenlemesi" faktörlerinde sınıf öğretmen adaylarının diğer öğretmen adaylarına göre daha düşük olduğu ve aradaki farkın istatistiksel açıdan anlamlı olduğu tespit edilmiştir $(\mathrm{p}<.05)$.

\section{Sonuç ve Tartışma}

Fen bilgisi, sınıf ve okul öncesi öğretmen adaylarının model ve modelleme, yaşam becerileri ve bilişötesi farkındalıklarına ait görüşlerinin bölümlere göre incelenmesi amacıyla gerçekleştirilen bu çalışmada aşağıdaki sonuçlara ulaşılmıştır:

1) Öğretmen adaylarının model ve modelleme konularındaki görüşleri:

Hem Model ve Modelleme Ölçeğinden hem de faktörlerinden elde edilen bulgulara göre fen bilgisi öğretmen adaylarının görüşlerinin sınıf ve okul öncesi öğretmen adaylarına göre daha iyi olduğu sonucuna ulaşılmıştır (Tablo 1-3). "Tam Bir Kopya Olarak Modeller" ve "Açıklayıcı Araçlar 
Olarak Modeller" faktörlerinde fen bilgisi öğretmen adayları ile sınıf öğretmenliği ve okul öncesi öğretmen adayları arasında istatistiksel açıdan anlamlı farklılıklar olduğu da tespit edilmiştir (Tablo 5). İlgili alanyazın incelendiğinde bu araştırmadan elde edilen sonuçlar ile paralellik (Yetim, 2015) ve farklı1ık (Ergin, Özcan ve Sarı, 2012) gösteren çalışmalar olduğu görülmektedir. Yetim (2015) modeller ile ilgili gerçekleştirdiği araştırmasında sosyal bilgiler, okul öncesi, Türkçe, sınıf, fen bilgisi ve ilköğretim matematik öğretmen adayları arasında dördüncü sınıflar düzeyinde istatistiksel açıdan anlamlı bir fark olduğunu, farkın sosyal ve Türkçe öğretmen adaylarının lehine olduğunu tespit etmiştir. Yetim (2015) ve Ergin, Özcan ve Sarı (2012) araştırmalarında üçüncü sınıfta öğrenim gören öğretmen adayları arasında bölümlere göre farklılık olmadığını tespit etmiştir.

2) Öğretmen adaylarının bilişötesi farkındalık konusundaki görüşleri:

Bilişötesi Farkındalık Envanterinden ve faktörlerinden elde edilen bulgulara göre fen bilgisi ve okul öncesi öğretmen adaylarının görüşlerinin sınıf öğretmen adaylarına göre daha yüksek seviyede olduğu sonucuna ulaşılmıştır (Tablo 1-3,7). İlgili alanyazın incelendiğinde bu araştırmadan elde edilen sonuçlar ile paralellik (Tüysüz, Karakuyu ve Bilgin, 2008) ve farklılık (Sezgin-Memnun ve Akkaya, 2012) gösteren çalışmalar olduğu görülmektedir. Tüysüz, Karakuyu ve Bilgin (2008) yaptıkları araştırmada sınıf öğretmenliği adaylarının bilişötesi farkındalık düzeylerinin düşük olduğunu, Sezgin-Memnun ve Akkaya (2012) araştırmasında ise sınıf öğretmenliği adaylarının bilişötesi farkındalık düzeylerinin daha yüksek olduğu sonuçlarını tespit etmişlerdir. Bu durum muhtemelen ilgili üniversiteleri tercih eden öğrencilerin bölümlere giriş puanlarıyla ilgili olabilir. Tüysüz, Karakuyu ve Bilgin, 2008 araştırmasında fen bilgisi öğretmen adaylarının lisans programlarında üst düzey düşünme becerilerini geliştiren derslerin olmasından dolayı fen bilgisi öğretmen adaylarının bilişötesi farkındalıklarının geliştiği sonucuna ulaşmıştır. $\mathrm{Bu}$ sonuçtan hareketle fen bilgisi ve okul öncesi öğretmen adaylarının sınıf öğretmen adaylarına göre bilişötesi farkındalıklarının daha iyi olmasının nedeni olarak, lisans programlarında yer alan derslerin üst düzey düşünme becerilerini geliştirecek nitelikte olması gösterilebilir.

3) Öğretmen adaylarının yaşam becerileri konusundaki görüşleri:

Yaşam Becerileri Ölçeğinden elde edilen bulgulara göre bölümler bazında öğretmen adaylarının görüşlerinin denk ve orta seviyede olduğu sonucuna ulaşılmıştır (Tablo 1-3). İlgili alanyazın incelendiğinde bu araştırmadan elde edilen sonuçlar ile paralellik gösteren çalışmalar olduğu görülmektedir (Özdemir, 2015; Turgut, 2019; Zorlu, Zorlu ve Dinç, 2019). Özdemir (2015) araştırmasında, fen bilgisi öğretmenlerinin "Yaşam Becerileri" kavramını farklı kavramlarla karıştırdıkları ve genel olarak orta düzeyde bilgiye sahip oldukları sonucuna ulaşmıştır. Zorlu, Zorlu ve Dinç (2019) çalışmasında "duygularla ve stresle başa çıkma" becerisinde fen bilgisi öğretmen adaylarının orta düzeyde olduklarını belirlemiştir. Fen bilgisi öğretmen adaylarının bu yaşam becerisinde orta seviyede olması kendini tanımada eksiklikler olması, derslerde beklenen başarının sağlanamaması, bulunduğu ortamdan memnuniyetsizlik gibi nedenlerden kaynaklanıyor olabilir. Turgut (2019) çalışmasında okulöncesi, sınıf ve fen bilgisi öğretmen adaylarının yaşam becerilerine ait görüşleri arasında fark olmadığı sonucuna varmıştır.

Fen bilgisi, sınıf ve okul öncesi öğretmen adaylarının model ve modelleme, yaşam becerileri ve bilişötesi farkındalık konularındaki görüşlerine göre yeteri düzeyde olmadıkları görülmektedir. Dolayısıyla bu konuların geliştirilmesi gereklidir. Çağımızdaki hızlı ilerleme ile bilgilerinin yanında becerilerini de geliştirmiş, üst düzey düşünen öğretmenlere ihtiyaç duyulmaktadır. Fen bilgisi, sınıf ve okul öncesi öğretmenleri yetiştirirken lisans eğitiminde modelleme yapabilecekleri, yaşam ve bilimsel süreç becerilerini dahil edebilecekleri öğrenme model, yöntem ve tekniklerin daha fazla kullanılması ile üst düzey düşünmeleri sağlanabilir. Bu doğrultuda model ve modelleme algılarının gelişmesi için derslerde modellemeye dayalı öğretim yöntemlerinin uygulanmasının katkılar sağlayacağ düşünülmektedir. 


\section{Kaynakça}

Adak, F. (2016). Fen bilgisi öğretmen adaylarının ve fen bilimleri ögretmenlerinin epistemolojik inançları ve bilişötesi farkındalıklarının incelenmesi. Yayımlanmamış yüksek lisans tezi, Mehmet Akif Ersoy Üniversitesi Eğitim Bilimleri Enstitüsü, Burdur.

Akın, A., Abacı, R. ve Çetin, B. (2007). Bilişötesi farkındalık envanteri'nin Türkçe formunun geçerlilik ve güvenilirlik çalışması. Kuram ve Uygulama Ĕ̆itim Bilimleri Dergisi, 7(2), 655680 .

Altunsoy, S. (2012). Fen ve teknoloji ögretmen adaylarının üstbilişsel stratejileri kullanmalarının özel görelilik teorisi konusundaki başarıları ve kuantum fiziğine yönelik tutumları üzerine etkisi. Yayımlanmamış yüksek lisans tezi, Gazi Üniversitesi Eğitim Bilimleri Enstitüsü, Ankara.

Aslan, A. ve Yadigaroğlu, M. (2013). Eğitim fakültelerindeki fen ve matematik lisansüstü öğrencilerinin model ve modelleme hakkındaki görüşleri. Eğitim ve Öğretim Araştırmalar Dergisi, 2(3), 123-132.

Ayas, A. (1995). Fen bilimlerinde program geliştirme ve uygulama teknikleri üzerine bir çalışma: İki çağdaş yaklaşımın değerlendirilmesi. Hacettepe Üniversitesi Ĕgitim Fakültesi Dergisi, $11,149-155$.

Aydın Güç, F. (2015). Matematiksel modelleme yeterliklerinin geliştirilmesine yönelik tasarlanan ögrenme ortamlarında öğretmen adaylarının matematiksel modelleme yeterliklerinin değerlendirilmesi. Yayımlanmamış doktora tezi, Karadeniz Teknik Üniversitesi Eğitim Bilimleri Enstitüsü, Trabzon.

Batı, K. (2014). Modellemeye dayalı fen ĕgitiminin etkinliği; bu ĕgitimin öğrencilerin bilimin doğası görüşleri ile eleştirel düşünme becerilerine etkisi. Yayımlanmamış yüksek lisans tezi, Hacettepe Üniversitesi Eğitim Bilimleri Enstitüsü, Ankara.

Bolat, Y. ve Balaman, F. (2017). Yaşam becerileri ölçeği: Geçerlik ve güvenirlik çalışması. İnsan ve Toplum Bilimleri Araştırmaları Dergisi, 6(4), 22-39.

Çiftçi, S. (2012). Web temelli eğitimde bilişüstü haritalama aracının ögrencilerin öz düzenleme becerilerine, bilişüstü farkındalıklarına ve başarılarına etkisi. Yayımlanmamış doktora tezi, Gazi Üniversitesi Eğitim Bilimleri Enstitüsü, Ankara.

Çolak, M. (2018). Ortaokul fen bilimleri dersinin 21. yüzyll becerilerini kazandırmadaki etkililiğine ilişkin ögrretmen görüşleri (Kayseri ili örneği). Yayımlanmamış yüksek lisans tezi, Erciyes Üniversitesi Eğitim Bilimleri Enstitüsü, Kayseri.

Deniz, D. (2017). Öğretmen adaylarının uyguladıkları model oluşturma etkinliklerinin onuncu sınıf öğrencilerinin üstbiliş farkındalıklarına etkisi. Bartın Üniversitesi Eğitim Fakültesi Dergisi, 2(6), 580-595. https://doi.org/10.14686/buefad.296924

Erduran Avc1, D. ve Kamer, D. (2018). Views of teachers regarding the life skills provided in science curriculum. Eurasian Journal of Educational Research, 77, 1-18. http://dx.doi.org/10.14689/ejer.2018.77.1

Erenler, S. (2017). Argüman temelli sorgulayıcı araştırma uygulamalarının fen bilgisi öğretmen adaylarının üstbilisssel farkındalık düzeyine ve yazma becerilerine olan etkisinin incelenmesi. Yayımlanmamış yüksek lisans tezi, Abant İzzet Baysal Üniversitesi Eğitim Bilimleri Enstitüsü, Bolu. 
Ergin, İ., Özcan, İ. ve Sarı, M. (2012). Farklı akademik unvanlara sahip fen öğretmenlerinin branşlara göre model ve modelleme hakkındaki görüşleri. Journal of Educational and Instructional Studies in The World, 2(1), 142-159.

Göksun-Orhan, D. ve Kurt-Aşkım, A. (2017). Öğretmen adaylarının 21. yy. öğrenen becerileri kullanımları ve 21. yy. öğreten becerileri kullanımları arasındaki ilişki. Eğitim ve Bilim Dergisi, 42(190), 107-130. http://dx.doi.org/10.15390/EB.2017.7089

Güneş, B., Gülçiçek, Ç. ve Bağc1, N. (2004). Eğitim fakültelerindeki fen ve matematik öğretim elemanlarının model ve modelleme hakkındaki görüşlerinin incelenmesi. Türk Fen Eğitimi Dergisi, 1(1), 35-48.

Hıdıroğlu, Ç. N. ve Bukova Güzel, E. (2015). Teknoloji destekli ortamda matematiksel modellemede ortaya çıkan üst bilişsel yapılar. Turkish Journal of Computer and Mathematics Education, 6(2), 179-208. https://doi.org/10.16949/turcomat.00708

Jaafar, W. M. W. ve Ayub, A. F. M. (2010). Mathematics self-efficacy and meta-cognition among university students. Procedia-Social and Behavioral Sciences, 8, 519-524. https://doi.org/10.1016/j.sbspro.2010.12.071

Kalley, M. ve Psillos D. (2001). Pre-School teachers' content knowledge in science: Their understanding of elementary science concepts and of issues raised by children's questions. International Journal of Early Years Education, 9(3), 165-179. https://doi.org/10.1080/09669760120086929

Karamustafaoğlu, S. ve Kandaz, U. (2006). Okul öncesi eğitimde fen etkinliklerinde kullanılan öğretim yöntemleri ve karş1laş1lan güçlükler. Gazi Eğitim Fakültesi Dergisi, 26(1), 65-81.

Karasar, N. (2011). Bilimsel araştırma yöntemleri. Nobel Yayınları.

Korkmaz, A. (2010). Illköğretim matematik ve sınıföğretmeni adaylarının matematiksel modellemeye yönelik görüşleri ve matematiksel modelleme yeterlikleri. Yayımlanmamış doktora tezi, Balıkesir Üniversitesi Eğitim Bilimleri Enstitüsü, Balıkesir.

Krell, M. ve Krüger, D. (2016). Testing models: A key aspect to promote teaching activities related to models and modelling in biology lessons?. Journal of BiologicalEducation, 50(2), 160173. https://doi.org/10.1080/00219266.2015.1028570

Kuvaç, M. (2014). Probleme dayalı öğrenmenin fen Bilgisi öğretmen adaylarının çevre bilinci ve üstbilişsel farkındalıklarına etkisi. Yayımlanmamış yüksek lisans tezi, İstanbul Üniversitesi Eğitim Bilimleri Enstitüsü, İstanbul.

Lee, D. T. ve Jones, M. G. (2005). Elementary teachers' selection and use of visual models. Journal of Science Education and Technol, 27(1), 1-29. https://doi.org/10.1007/s10956-017-9705-1

Milli Eğitim Bakanlı̆̆ [MEB] (2005). İlköğretim fen ve teknoloji dersi öğretim programı. MEB Yayınları.

Milli Eğitim Bakanlığı [MEB] (2016). Fen Bilimleri Dersi Öğretim Programları (İlkokul ve Ortaokul 3, 4, 5, 6, 7 ve 8. Siniflar). MEB Yayınlar1.

Milli Eğitim Bakanlığı [MEB] (2018). Fen Bilimleri Dersi Öğretim Programları (İlkokul ve Ortaokul 3, 4, 5, 6, 7 ve 8. Sintflar). MEB Yayınlar1..

Murat, A. (2018). Fen bilgisi öğretmen adaylarının 21.yüzyll becerileri yeterlik algılart ile STEM'e yönelik tutumlarının incelenmesi. Yayımlanmamış yüksek lisans tezi, Fırat Üniversitesi Eğitim Bilimleri Enstitüsü, Elazığ. 
Fen Bilgisi, Sınıf ve Okulöncesi Öğretmen Adaylarının Model ve Modelleme, Yaşam...

Özata-Yücel, E. ve Kanyılmaz, B. M. (2018). Fen bilimleri dersi öğretim programında yer alan yaşam becerilerinin ilkokul öğrencilerine kazandırılmasına yönelik öğretmen görüşlerinin değerlendirilmesi. Ĕğitimde Nitel Araştırmalar Dergisi, (6)3, 10-33. https://doi.org/10.14689/issn.2148-2624.1.6c3s.1m

Özdemir, A. A. (2017). Ë̆itim fakültelerindeki fen bilgisi ögretmen adaylarının model ve modelleme hakkındaki düşüncelerinin analizi. Yayımlanmamış yüksek lisans tezi, Kahramanmaraş Sütçü İmam Üniversitesi Eğitim Bilimleri Enstitüsü, Kahramanmaraş.

Özdemir, D. (2015). Fen bilimleri öğretmenlerinin yaşam becerileri hakkındaki görüşleri. Yayımlanmamış yüksek lisans tezi, Mehmet Akif Ersoy Üniversitesi, Eğitim Bilimleri Enstitüsü, Burdur.

Partnership for 21st Century Learning [p21] (2015). P21 framework definitions. Retrieved from http://www.p21.org/storage/documents/docs/P21_Framework_Definitions_

New_Logo_2015.pdf. Erişim Tarihi: Mayıs 2019.

Schraw, G. ve Dennison, R. S. (1994). Assessing metacognitive awareness. Contemporary Educationa lPsychology, 19(4), 460-475.

Sezgin Memnun, D. ve Akkaya, R. (2012). Matematik, fen ve sınıf öğretmenliği öğrencilerinin bilişötesi farkındalıklarının bilişin bilgisi ve düzenlenmesi boyutları açısından incelenmesi. Kuramsal Eğitimbilim Dergisi, 5(3), 312-329.

Şahin, S. (2015). Fen bilgisi öğretmen adaylarının bilişüstü farkındalık düzeyleri ile problem çözme becerilerinin incelenmesi. Yayımlanmamış yüksek lisans tezi, Gazi Üniversitesi Eğitim Bilimleri Enstitüsü, Ankara.

Turgut, S. (2019). Öğretmen adaylarının yaşam becerilerine yönelik görüşlerinin incelenmesi Yayımlanmamış yüksek lisans tezi, Burdur Mehmet Akif Ersoy Üniversitesi Eğitim Bilimleri Enstitüsü, Burdur.

Tüysüz, C., Karakuyu, Y. ve Bilgin, İ. (2008). Öğretmen adaylarının üst biliş düzeylerinin belirlenmesi. Abant İzet Baysal Sosyal Bilimler Enstitüsü Dergisi, 2(17), 147-158. https://doi.org/10.11616/AbantSbe.225

Ülger, M. (2003). İlköğretim altıncı sınıf sosyal bilgiler dersi Osmanlı Devleti'nin kuruluşu ünitesinde ögrenme stratejilerini öğrenmenin öğrenci erişisine etkisi. Yayımlanmamış yüksek lisans tezi, Gazi Üniversitesi Eğitim Bilimleri Enstitüsü, Ankara.

Ümmet, D. ve Demirci, G. (2017). Yaşam becerileri eğitimi kapsamında yürütülen grupla psikolojik danışma uygulamasının ortaokul öğrencilerinin iyi oluşları üzerindeki etkisi. Marmara Üniversitesi Atatürk Ĕ̈itim Fakültesi Ĕ̈itim Bilimleri Dergisi, 45(45), 153-170. https://doi.org/10.15285/maruaebd.263879

Ünal, S., Çoștu, B. ve Karataş, F. Ö. (2004). Türkiye'de fen bilimleri eğitimi alanındaki program geliştirme çalışmalarına genel bir bakış. Gazi Eğitim Fakültesi Dergisi, 24(2), 183-202.

Weaver, S. O. (2012). The effects of metacognitive strategies on academic achievement, metacognitive awareness, and satisfaction in an under graduate online education course. Unpublishing doctoral dissertation, University of South Alabama Graduate Faculty, South Alabama.

Yetim, H. (2015). Farkl ĕgitim düzeylerindeki öğrencilerin ve ögretmen adaylarının modellerle ilgili görüşlerinin karşılaştırılması. Yayımlanmamış yüksek lisans tezi, Karadeniz Teknik Üniversitesi Eğitim Bilimleri Enstitüsü, Trabzon. 
Zorlu, Y. ve Sezek, F. (2019). Investigation of the effects of group research method of applying modeling based teaching method in the particle structure and properties of matter unit on constructivist learning. Sakarya UniversityJournal of Education, 9(3), 455-475. https://doi.org/10.19126/suje.481295

Zorlu, Y., Zorlu, F. ve Dinç, S. (2019). Fen bilgisi öğretmen adaylarının yaşam becerileri ile bilişüstü farkındalıkları arasındaki ilişkilerin incelenmesi. Necatibey Eğitim Fakültesi Elektronik Fen ve Matematik Ë̆itimi Dergisi, 13(1), 302-327. https://doi.org/10.17522/balikesirnef.511546 